\title{
Clinical utility of fetal echocardiography: an Egyptian center experience
}

\author{
Marwa Moustapha Al-Fahham ${ }^{1,3^{*}}$, Nada Ayman Gad', Ahmed Ramy Mohamed Ramy² and \\ Nevin Mamdouh Habeeb ${ }^{1}$
}

\begin{abstract}
Background: The impact of early diagnosis of fetal cardiac abnormalities on the postnatal outcome has been controversial in literature. We aimed to evaluate the role of fetal echocardiography (FE) as a diagnostic tool for early detection and proper management of fetal cardiac abnormalities, study the indications of referral and detect the perinatal outcome in our institution.

Results: This is a cross-sectional observational and descriptive study that included one hundred and one singleton pregnant women (101 fetuses) who were referred for FE over a period of one year. Indications for referral and perinatal risk factors were documented. FE and postnatal transthoracic echocardiography were done. Fetal cardiac abnormalities were detected in $46.5 \%$ of cases. Congenital heart defects (CHDs) in 34.6\%, fetal arrythmias in 9.9\%, cardiomyopathy in $2.9 \%$ and cardiac mass (Rhabdomyoma) in $1 \%$ (combined structural and rhythm abnormalities were observed in two fetuses). Of the CHDs, complex heart lesions were diagnosed in $57.1 \%$, common atrioventricular canal in $28.6 \%$ and conotrunchal anomalies in $14.3 \%$. Of the ten cases with fetal arrythmias, five fetuses had tachyarrhythmias, four had ectopics and one fetus had congenital heart block in association with maternal lupus. The indications for referral were abnormal obstetric ultrasound (52.5\%), maternal medical illnesses (23.8\%), multiple neonatal deaths (13.9\%) and positive family history of CHD (10.9\%). The number of fetuses with cardiac abnormalities was significantly higher than those without cardiac abnormalities in mothers not exposed to perinatal risk factors $(p=0.009)$ and was statistically lower in mothers exposed to perinatal risk factors $(p=0.005)$. FE showed $100 \%$ accuracy in diagnosing complex lesions, common atrio-ventricular canals, cono-truncal anomalies, cardiac masses and fetal arrhythmias. It missed two cases of tiny muscular ventricular septal defects and one case of aortic coarctation. Cases of fetal supraventricular tachycardia were successfully treated in-utero.
\end{abstract}

Conclusions: CHDs exist in fetuses with no underlying perinatal risk factors. FE can accurately diagnose most of the cardiac anomalies though few errors remain challenging (aortic coarctation). It also offers a good chance for successful early life-saving management of some types of fetal arrhythmia.

Keywords: Fetal echocardiography, Congenital heart disease, Fetal arrhythmia, Prenatal diagnosis, Perinatal risk factors

*Correspondence: m_alfahham5m@hotmail.com; dr.m.alfahham@sih-kw. com

1 Pediatric Department, Pediatric Cardiology Unit, Faculty of Medicine, Ain Shams University, Ramsis Street, Abbasia, Cairo 11566, Egypt

Full list of author information is available at the end of the article

\section{Background}

$\mathrm{CHD}$ is the most common congenital anomaly that occurs in 6-12 per 1000 live births [1]. Several risk factors have been incriminated in the pathogenesis of $\mathrm{CHD}$ [2]. These include consanguinity [3], maternal medical illnesses [4], teratogenic exposures [5], fetal chromosomal and extra-cardiac abnormalities [6]. However; a major 
number of cases do exist without any detectable prenatal risk factors [7].

The impact of prenatal diagnosis of CHD on the postnatal outcomes has been controversial. Several studies have shown that it decreased neonatal morbidity and mortality; usually of the duct-dependent types [8] as it provides the opportunity for a controlled elective delivery at a tertiary care center with a specialized perinatal cardiac and cardio-thoracic surgical services [9].Moreover, it helps the detection of concomitant fetal chromosomal and extra-cardiac anomalies, assists in antenatal and postnatal management planning and offers better parental counseling [10]. Other studies found no benefit on neonatal outcomes [11].

FE is also the most widely used diagnostic modality for the detection of fetal arrhythmias [12] and evaluation of its consequences such as valve regurgitation, myocardial dysfunction and development of hydrops fetalis [13].

FE is used to detect cardiac anomalies in high risk specific cases [14]; though its use as a routine screening tool for all pregnancies is still not well-established [15]. Most of the referrals are still based on the presence of abnormal 4 chamber view on obstetric ultrasound scan or the presence of a favoring prenatal risk factor despite that only $10 \%$ of the affected children have such an identifiable predisposing factor [16]. In this study, we aimed to evaluate the role of $\mathrm{FE}$ as an evolving diagnostic tool in our institution for early detection and proper management of fetal cardiac abnormalities; including fetal arrhythmia and to detect the perinatal outcome of the affected fetuses. We also studied the distribution of the well- known perinatal risks in our community. Up to the best of our knowledge, this is the first Egyptian study that documents the utility of FE in the management of fetuses with suspected cardiac abnormalities.

\section{Methods}

This is a cross-sectional analytical and descriptive study that included 101 singleton pregnant women (101 fetuses) referred for FE over a period of 1 year from November 2014 till October 2015. The study was conducted at the ultrasound special care unit for the fetus at the obstetrics and gynecology hospital in collaboration with the pediatric cardiology and echocardiography unit at a university hospital. Detailed history was taken from all pregnant mothers which included maternal and paternal ages, consanguinity, obstetric history (gestational age (GA), parity, abortions, still births, assisted reproductive technology (ART), neonatal deaths) and family history of CHD, chromosomal or other congenital anomalies. Prenatal risk factors were extracted (active and passive smoking, maternal medical illnesses, infections, medications and exposure to radiation). Indications for referral were reported and the original indication was chosen in patients who fell in more than one referral category.

\section{Fetal echocardiography}

FE was done for the referred cases to detect any structural or rhythm abnormalities in the fetal heart according to the guidelines and standards of the American Society of Echocardiography for performance of fetal echocardiogram [17] using GE Voluson E6 high-end 4DOB/GYN ultrasound machine and transducer probe with a frequency range of 5-8 $\mathrm{MHz}$. A standard two-dimensional (2D), m-mode, color flow (CF), Doppler echocardiography examinations were done. Views included four chamber, five chamber, long axis (left and right ventricular outflow), 3 -vessel and tracheal, ductal, and aortic arch views.

\section{Neonatal echocardiography (NE)}

$\mathrm{NE}$ was done within $48 \mathrm{~h}$ of delivery; based on the urgency of each individual case; using Vivid 7 machine (GE N-3190, Horton, Norway) and probe 10SGE ultrasound (SN 66958 PD0/USA). The studied population was classified into two groups according to the presence (group A) or absence (group B) of fetal cardiac abnormalities. Structural CHDs were categorized into common AV canal, conotrunchal anomalies, septal defects, complex lesions and coarctation. When abnormalities were found; prognosis and management were discussed with the parents and the referring obstetrician. Arrangement for controlled elective delivery in our tertiary center under the supervision of expert pediatric cardiologists and neonatologists was planned for all fetuses diagnosed with cardiac abnormalities in-utero. In-utero antiarrythmic therapy was offered in some cases with fetal arrhythmia.

\section{Statistical analysis}

Data were analyzed using Statistical Program for Social Science (SPSS) version 18.0. Quantitative data were expressed as mean \pm standard deviation (SD). Qualitative data were expressed as frequency and percentage. Independent sample t-test was used to compare two means and Chi-square test was used to compare proportions between two qualitative parameters. $P$ value of $<0.05$ was considered significant. Sensitivity, specificity, positive and negative predictive values and accuracy of FE were calculated to assess its ability to detect the cardiac abnormality in utero and to detect the same cardiac abnormality in the postnatal period.

\section{Results}

The study involved 101 singleton pregnant women (101 fetuses) whose ages ranged from 17 to 42 years with a mean and SD of $(28.09 \pm 5.19)$ years. All the 
referred cases had undergone routine obstetric ultrasound before referral to detect multiple gestation and to diagnose any extra- cardiac abnormality such as hydrops fetalis, increased first trimester nuchal translucency, abnormal fetal heart beats and abnormal four and five chamber views. The timing of the routine obstetric scan ranged from 16 to 20 weeks with a mean and SD of $(18 \pm 2.5)$ weeks. Their gestational age (GA) at referral for FE ranged from 16 to 38 weeks with a mean and SD of $(25.2 \pm 3.4)$ weeks and $70.5 \%$ of the cases were referred after 22 weeks. Their paternal ages ranged from 24 to 48 years with mean and SD of $(32.13 \pm 5.39)$ years. The mean values of maternal, paternal and gestational ages were $28.45 \pm 5.37$ years, $32.43 \pm 5.69$ years and $29.21 \pm 5.99$ weeks respectively in group $\mathrm{A}$ and $27.78 \pm 5.05$ years, $31.87 \pm 5.15$ years and $27.64 \pm 4.95$ weeks respectively in group B with no statistically significant differences between both groups $(p>0.05)$.

Table 1 Indications for referrals

\begin{tabular}{llc}
\hline Indications for FE & $\begin{array}{c}\text { Number } \\
(\boldsymbol{n}=\mathbf{1 0 1})\end{array}$ & Percentage (\%) \\
\hline Abnormal Obstetric US & 53 & 52.5 \\
Cardiac configuration & 46 & 45.5 \\
Fetal rhythm & 7 & 6.9 \\
Maternal medical illnesses & 23 & 22.8 \\
Diabetes & 11 & 10.9 \\
Lupus & 7 & 6.9 \\
Hypertension & 5 & 4.9 \\
Multiple neonatal deaths & 14 & 13.9 \\
Positive family history of CHD & 11 & 10.9 \\
\hline
\end{tabular}

US: Ultrasound

\section{Indications for referrals and perinatal risk factors}

Table 1 shows the indications of FE.

Sixty-six pregnant mothers $(65.3 \%)$ had perinatal risk factors for CHD and 35 mothers (34.6\%) had not shown any perinatal risk factors and were referred for FE on basis of suspicious routine obstetric scan. One perinatal risk factor was detected in 31 cases (30.7\%), two risk factors in 19 cases $(18.8 \%)$ and three or more risk factors were detected in 16 cases $(15.8 \%)$. Consanguinity was found in 32 cases (31.7\%), maternal exposure to radiation in $13(12.9 \%)$, passive smoking in 12 (11.9\%), multiple abortions in $8(7.9 \%)$, maternal intake of medications in $5(4.9 \%)$ cases (corticosteroid therapy in 3 mothers, anti-epileptic medication in one mother and non-steroidal anti-inflammatory medication on one mother). Two cases (1.9\%) had been conceived via assisted reproductive technology.

Of the 53 cases referred on basis of suspicious obstetric scan, thirty eight cases $(71.7 \%)$ proved to have positive cardiac abnormalities on fetal scanning. On the other hand, nine fetuses who had positive cardiac findings on FE scanning had not revealed any suspicious findings on obstetric ultrasound and were referred for FE screening for the presence of associated risk factors. Of the total population, discrepancies between the routine obstetric scan and the FE findings were encountered in 21 cases (Table 2).

The number of fetuses with positive cardiac findings was significantly higher than those without cardiac abnormalities in mothers not exposed to any perinatal risk factors and in mothers referred on basis of a suspicious obstetric US (abnormal cardiac configuration or abnormal fetal rhythm) and was significantly lower than fetuses with normal hearts in mothers exposed to perinatal risk factors. Table 3 shows the comparison between

Table 2 Discrepancies between routine obstetric ultrasound scan and FE

\begin{tabular}{|c|c|c|c|}
\hline Case number & Obstetric US & $\mathrm{FE}$ & Post natal assessment \\
\hline \multicolumn{4}{|c|}{ Cases with suspicious Obstetric US and normal FE } \\
\hline$(18,55,61-69)$ & Suspicious & Normal & Normal \\
\hline (21) and (56) & Suspicious & Normal & Not done (Lost follow up) \\
\hline (43) & Suspicious & Normal & Not done (IUFD) \\
\hline \multicolumn{4}{|c|}{ Cases with positive findings by FE and unsuspicious obstetric US } \\
\hline (39) & Normal & Cono-trunchal anomaly & Not done (Lost follow up) \\
\hline$(45,52)$ & Normal & Complex CHD & Confirmed \\
\hline (46) & Normal & Complex CHD & Not done (Stillbirth) \\
\hline (51) & Normal & Common AV canal & Not done (Lost follow up) \\
\hline (58) & Normal & Prolonged PR interval & confirmed \\
\hline (72) & Normal & Atrial tachycardia & Not done (Elective termination) \\
\hline$(75,82)$ & Normal & Common AV canal & Confirmed \\
\hline
\end{tabular}

CHD congenital heart defect, FE fetal echocardiography, NE neonatal echocardiography, US ultrasound 
Table 3 Comparison between both groups as regards to the perinatal risk factors and indications for referral

\begin{tabular}{lclll}
\hline & Group A $(\boldsymbol{n}=\mathbf{4 7})$ & Group B $(\boldsymbol{n}=\mathbf{5 4 )}$ & Chi square $\boldsymbol{X}^{\mathbf{2}}$ & $\boldsymbol{P}$ \\
\hline Abnormal Cardiac configuration by obstetric US & 31 & 15 & 14.769 & $\mathbf{0 . 0 0 0}^{*}$ \\
Fetal arrhythmia by obstetric US & 7 & - & 8.641 & $\mathbf{0 . 0 0 3}^{*}$ \\
No perinatal risk factors & 23 & 12 & 6.914 & $\mathbf{0 . 0 0 9}^{*}$ \\
Perinatal risk factors & 24 & 42 & 7.919 & $\mathbf{0 . 0 0 5 ^ { * }}$ \\
One risk factor & 14 & 17 & 0.34 & 0.854 \\
Two risk factors & 7 & 12 & 0.884 & 0.347 \\
$\geq 3$ risk factors & 3 & 13 & 5.899 & 0.151 \\
\hline
\end{tabular}

US ultrasound

$P<0.05$ considered significant

the studied groups as regards to the distribution of the perinatal risk factors and the indications of FE.

\section{Fetal echocardiography}

Difficulties in obtaining adequate echocardiographic views were encountered in only 4 cases; two of them due to the anterior position of the fetal vertebral column obscuring the view, one case due to maternal obesity and one case due to inappropriate timing (late referral).

Fetal cardiac abnormalities were detected in 47 fetuses (46.5\%). CHDs in 35 (34.6\%), fetal arrhythmia in $10(9.9 \%)$, cardiomyopathy in $3(2.9 \%)$ fetuses and cardiac mass (Rhabdomyoma) in only one fetus (1\%) [Two cases had combined pathologies (one fetus had common AV canal and SVT, the other had cardiomyopathy and frequent PVCs)]. Of the structural CHDs, complex heart lesions were found in 20 (57.1\%), common atrioventricular canal in $10(28.6 \%)$ and conotrunchal anomalies in 5 fetuses (14.3\%).Of the fetal arrythmias, five fetuses had tachyarrhythmias, four had ectopics and one fetus had congenital heart block in association with maternal lupus. Combined structural and rhythm abnormalities were observed in two fetuses (Table 4). Follow up FE examinations were needed in 26 cases (25.7\%) due to disease progression (23 cases), obscuring fetal position ( 2 cases) and maternal distress in one case.

Table 4 Management decisions and outcome of fetuses with cardiomyopathy, rhythm abnormalities and cardiac mass

\begin{tabular}{|c|c|c|}
\hline Diagnosis & Decision & Outcome \\
\hline \multicolumn{3}{|l|}{ Cardiomyopathy } \\
\hline Case no (35) & Prevention of termination/regular FUP & Resolved intrauterine \\
\hline Case no (88) Associated with frequent PVCs & Prevention of termination/regular FUP & IUFD \\
\hline Case no (91) & Prevention of termination/regular FUP & Lost FUP \\
\hline $\begin{array}{l}\text { Cardiac mass } \\
\text { (Rhabdomyoma) }\end{array}$ & Prevention of termination/regular FUP & spontaneous regression \\
\hline \multicolumn{3}{|l|}{ Arrhythmias } \\
\hline Case no (41) Frequent PVCs & Prevention of termination/regular FUP & Resolved intrauterine \\
\hline Case no (50) Atrial fibrillation & Immediate induction of labor & Mother refused, DAMA signed \\
\hline Case no (58) Congenital heart block & Admission under obstetric care/regular FUP scanning & Arranged for neonatal pacemaker \\
\hline Case no (70) Atrial flutter with variable conduction & Regular FUP & Lost FUP \\
\hline Case no (72) Atrial tachycardia & Antiarrhythmic given without improvement & Elective termination due to severe hydrops \\
\hline $\begin{array}{l}\text { Case no (78) } \\
\text { Frequent PACs }\end{array}$ & Regular FUP & Resolved intrauterine \\
\hline $\begin{array}{l}\text { Case no (79) Frequent PACs } \\
\text { Case no (84) }\end{array}$ & Regular FUP & Resolved intrauterine \\
\hline SVT + common AV canal & Antiarrhythmic/regular FUP & Postnatal Antiarrhythmic therapy \\
\hline Case no (88) & Discussed above & Discussed above \\
\hline Case no (95) SVT & Antiarrhythmic/regular FUP & Post natal antiarrhythmic therapy \\
\hline
\end{tabular}




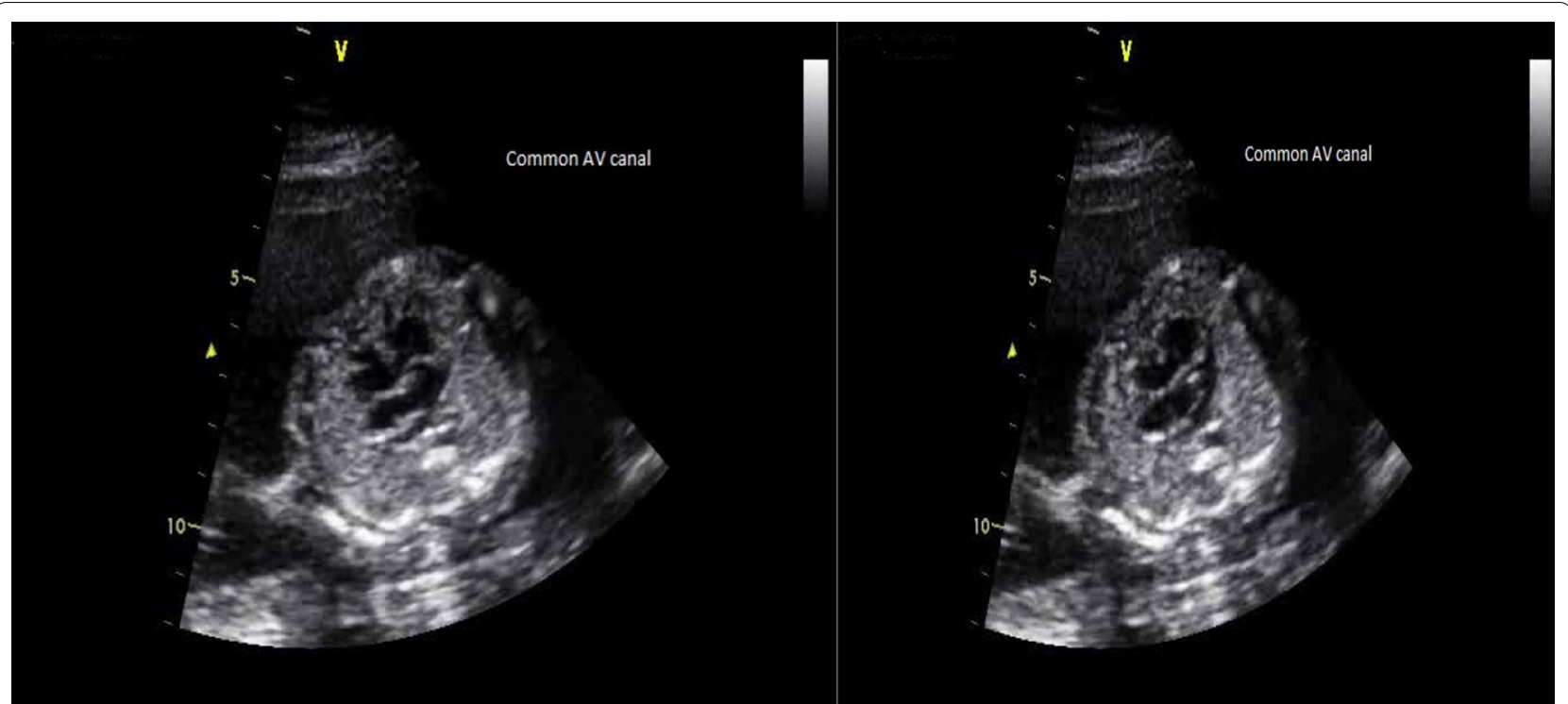

Fig. 1 Common AV canal in cases no (75) and (81)

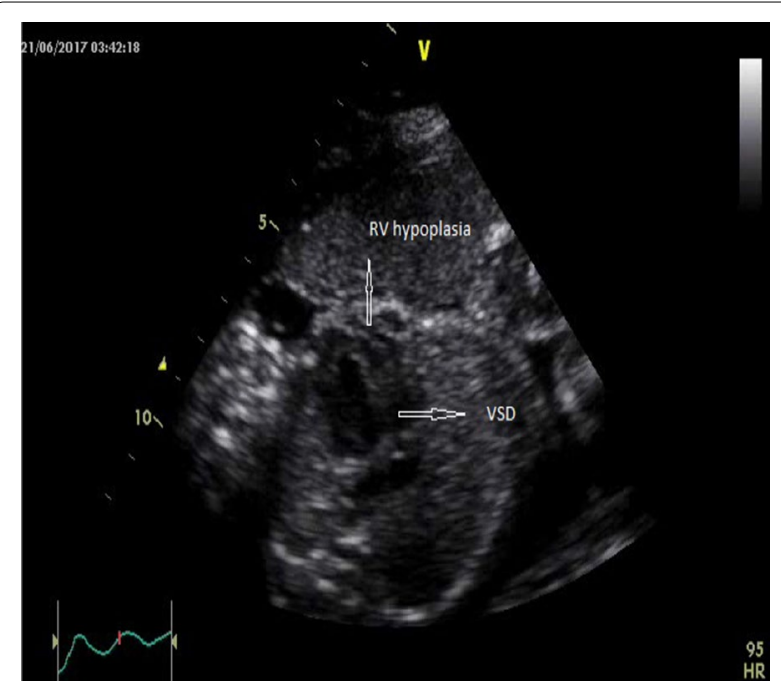

Fig. 2 Complex congenital heart disease in case no (98)

Figures 1, 2 and 3 demonstrate some of the encountered fetal cardiac abnormalities.

\section{Decision and outcome}

The decisions taken regarding fetuses with CHD were watchful follow up and arranging for elective delivery in our tertiary care center which offers highly qualified cardiac and cardiothoracic services. Of the total number of population, term delivery occurred in 55 cases, preterm in 2 cases, Intrauterine fetal death (IUFD) in 8 cases, abortion in one case, stillbirth in one case and elective

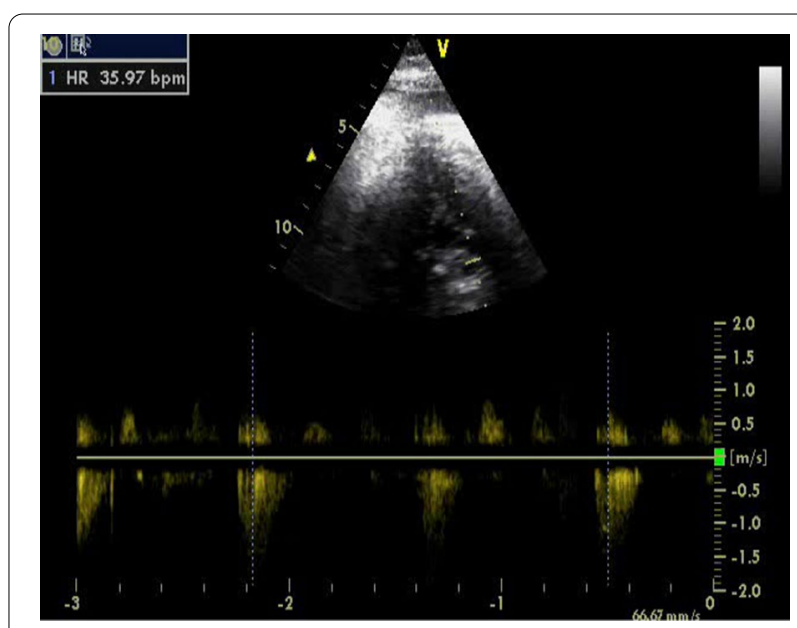

Fig. 3 Fetal heart block in an obese lupus mother

termination in one case. Twenty-seven cases lost follow up, five cases were cured in-utero and discharge against medical advice (DAMA) was signed in one case.

Table 4 shows the decisions taken and outcome of fetuses with arrhythmias, cardiomyopathy and cardiac mass.

Of the twenty fetuses diagnosed with complex heart lesions, three fetuses died in-utero, one was stillbirth, six lost follow up and ten were born alive and received the required postnatal cardiac care. Of the nine fetuses with common AV canal (excluding the case with associated arrhythmia), one died in-utero, three lost follow 
up and five were born alive. Of those five fetuses with conotrunchal anomalies, two lost follow up and three were born alive.

\section{Neotnatal echocardiography}

NE was done for 57 neonates (21 cases of group A and 36 cases of group B). FE was $100 \%$ sensitive and accurate in diagnosing complex heart lesions, atrio-ventricular septal defects, conotrunchal anomalies and cardiac mass.

Table 5 shows the sensitivity, specificity, predictive values and accuracy of FE in the diagnosis of each of the specific fetal cardiac abnormalities (after excluding cases that were cured in-utero, died (IUFD or still birth), electively terminated and cases which lost follow up).

Two cases with tiny muscular ventricular septal defects and one case with coarctation of aorta were missed by FE and were diagnosed postnatally. The routine obstetric US scan of the case with aortic coarctation was done at 19 weeks gestation and was unsuspicious of any cardiac abnormalities. The case was referred for FE in the view of maternal history of multiple previous abortions. FE was done at the age of 20 weeks gestation and revealed mild dilatation of the left ventricle. A second look was decided for the case to monitor the disease progression but the mother did not return back for follow up until after delivery when NE revealed mild coarctation.

\section{Discussion}

In our fetal care unit; almost all pregnant women undergo a minimum of one obstetric ultrasound that includes fetal heart scanning based on the four and five chamber views to screen for CHD. A detailed FE scanning by an expert pediatric cardiologist is indicated when findings in these views do not fulfill the normal criteria [18]. Deviation from normality includes abnormal cardiac position or axis, chamber dilatation and or asymmetry, cardiomegaly and fetal arrhythmia [19]. Obtaining only a normal four chamber view is still not sufficient to exclude underlying cardiac anomalies [20], hence; the routine obstetric scan may not be the ideal tool to screen for fetal cardiac abnormalities [21]. FE is more sensitive and more specific in the prenatal detection of $\mathrm{CHD}$ when compared to the routine obstetric scanning that can miss a large number of cases [22]. In a study done by Archiron et al. [23], the rate of detection of CHD was raised from $48 \%$; when relying on the four chamber view alone; to $78 \%$ when other views were incorporated. Similarly, Carvalho et al. [24] reported a detection rate of $75 \%$ with extended screening. In this series, discrepancies between the routine obstetric scan and the FE were encountered in 21 cases. Of which; nine cases showed positive findings by FE though their routine obstetric scan was marked as "Normal". This highlights the need to raise the awareness of the obstetricians and the obstetric ultra- sonographers that limited screening of the fetal heart by the 4- and 5chamber views may not be sufficient to totally exclude an underlying fetal cardiac abnormality.

In this series, more than half of the cases (52.5\%) were referred for suspected cardiac abnormalities on routine obstetric ultrasound (abnormal cardiac configuration in $45.5 \%$ and abnormal fetal rhythm in $6.9 \%$ ) and of the referred cases, the percentage of positive FE scans was $71.7 \%$. In a study done by Meyer-Wittkopf et al. [18], cases referred on basis of suspicious cardiac configuration and abnormal fetal rhythm were $(26 \%)$ and $(5.7 \%)$ of their studied population respectively and the percentage of $\mathrm{FE}$ scans confirmed positive for CHD was $78 \%$. Also in a study done by Chitra and Vijayalakshmi [25], abnormal obstetric scan was the indication of referral in $26.8 \%$ of their studied population. This highlights the role of obstetric US scanning as an important screening tool for fetal structural and rhythm abnormalities, though; unfortunately we were not able to compare between the accuracy of the obstetric and the FE scanning as most of the referral letters included "suspected cardiac views" without mentioning a definitive provisional diagnosis.

Currently, FE is reserved for high risk pregnancies where higher incidence of CHD is traditionally expected [22], though; previous studies reported that most of the cases of CHDs occur in low risk population with no identifiable prenatal risk factors $[7,16,26]$. In this series, the number of fetuses with positive cardiac findings was significantly higher than those without cardiac abnormalities in mothers not exposed to any perinatal risk factors and was significantly lower than fetuses with normal hearts in mothers exposed to perinatal risk factors. This

Table 5 Comparison between fetal and postnatal echocardiography

\begin{tabular}{llllllll}
\hline & FE & NE & Sensitivity (\%) & Specificity (\%) & PPV (\%) & NPV (\%) & Accuracy (\%) \\
\hline Complex CHD & 10 & 10 & 100 & 100 & 100 & 100 & 100 \\
Common AV canal* & 6 & 6 & 100 & 100 & 100 & 100 & 100 \\
Conotrunchal anomaly & 3 & 3 & 100 & 100 & 100 & 100 & 100 \\
Cardiac mass & 1 & 1 & 100 & 100 & 100 & 100 & 100 \\
\hline
\end{tabular}

FE fetal echocardiography, $P P V$ positive predictive value, NPV negative predictive value, NE neonatal echocardiography

* Including the case with associated arrhythmia 
matches with Nayak et al. [22] who advocated that FE should be included as a routine antenatal scanning for all pregnancies irrespective of the perinatal risk factors for congenital cardiac anomalies as they found no statistical difference in the incidence of these anomalies between low risk versus high risk pregnancies; moreover, they even encountered a higher number of cases with CHDs in the low risk group.

The ideal timing for prenatal echocardiography is 18-22 weeks gestation [17]. In this series, the mean value of gestational age on first FE scanning was $(25.2 \pm 3.4)$ weeks. This compares favorably with previous studies $[25,27,28]$.

In this study, we detected cardiac abnormalities in $46.5 \%$ of the referred fetuses. CHDs in $34.6 \%$, fetal arrythmias in $9.9 \%$, cardiomyopathy in $2.9 \%$ and cardiac mass (Rhabdomyoma) in $1 \%$. Of the CHDs, complex heart lesions were diagnosed in $57.1 \%$, common atrioventricular canal in $28.6 \%$ and conotrunchal anomalies in $14.3 \%$. In their study, Chitra and Vijayalakshmi [25] detected CHD in $18.2 \%$, fetal arrhythmias in 3.6\% and rhabdomyomas in $0.6 \%$ of their studied population. Among their CHD group, complex lesions were detected in $70 \%$ of cases. Also, Meyer-Wittkopf et al. [18] detected CHD in $24.5 \%$. The differences in the detection rate between different studies can be attributed to the significant variations in the incidence of CHD that do exist between different populations belonging to different ethnicities [29].

In a study done by Zhang et al. [30], the sensitivity and specificity of FE in detecting CHD was $68.5 \%$ and $99.8 \%$ respectively whereas, Soongswang et al. [31] detected sensitivity, specificity, positive predictive value, negative predictive value and accuracy of 96.9\%, 90.6\%, 84.2\%, $98.3 \%$ and $92.8 \%$ respectively. In this series, postnatal studies revealed that FE was able to diagnose correctly all cases of CHD (conotrunchal anomalies, atrioventricular canal, and complex heart lesions), cardiomyopathy, and cardiac mass after exclusion of cases which died, cured in- utero and cases which lost follow up. We encountered three false negative diagnosises; two small restrictive ventricular septal defects (VSDs) and one coarctation of aorta. Neither of our false negative cases had experienced any deteriorating hemodynamic consequences in the postnatal period and they had come only to medical attention in the view of recruitment for neonatal echocardiography confirmation. The types of cardiac lesions missed in our study match favorably with the study done by Meyer-Wittkopf et al. [18] who detected a sensitivity of $98 \%$ in the prenatal diagnosis of CHD by FE. The difficulty in the prenatal diagnosis of aortic coarctaion is well-known in literature [32] and had been reported in previous studies $[33,34]$. This confirms the need for sequential follow up studies as some cardiac lesions have an evolving nature [35].

Fetal arrhythmias account for nearly $10-20 \%$ of total referrals for FE [12]. Most of which are in the form of frequent ectopic beats with the atrial ectopics being much more common than those of ventricular origin. Tachyarrythmias are diagnosed when fetal heart rate is above 180 beats per minute. They include sinus, atrial, supraventricular and ventricular tachycardia [36]. Fetal bradyarrythmia are diagnosed when fetal heart rate is persistently below 100 beats per minute which can be due to blocked atrial bigemeny or atrio-ventricular block or sinus bradycardia (rare) [12]. In this series, we detected arrhythmias in $9.9 \%$ of the studied population. Only one case had an underlying CHD. Of the 10 cases with fetal arrhythmias, five cases had tachyarrhythmia, 4 cases had ectopics and one case had congenital heart block in association with maternal lupus. Cases with ectopics had resolved in the intrauterine period except for the one with associated cardiomyopathy which died in-utero. The case with congenital heart block was followed up meticulously; regular follow up scanning showed improvement in the heart rate $(>55 / \mathrm{min})$ and future planning for neonatal pacemaker was arranged prenatally. Both cases of supraventricular tachycardias (SVT) were successfully treated during the fetal life. Successful treatment of fetal arrhythmia in utero and spontaneous resolution of premature atrial contractions had been also reported by Soongswang et al. [31]. Of their 17 cases diagnosed with fetal arrhythmia, Chitra and Vijayalakshmi [25] reported bradycardia in 10 cases, tachyarrythmias in 5 cases, ectopics in two cases and complete heart block in one case with maternal lupus. They also observed lower association between fetal arrhythmia and underlying structural heart diseases.

Early prenatal diagnoses provides the neonate with a better care in-utero and in the post natal period. Moreover; it allows for early family counseling which allows the parents to be psychologically and financially prepared to accept such a child [37] as it offers them time to be fully aware of the pathophysiology of the detected anomaly; also the treating physician will have enough time to explain the severity and discuss the prognosis with parents so they can be able to take a decision regarding the course of pregnancy. Missing such cases on routine obstetric scanning or discovering them at late pregnancy would have rendered decision taking more difficult [22]. Management of a neonate with an antenatal diagnosis of CHD necessitates coordinate collaboration between obstetricians, neonatologists, pediatric cardiologists, fetal echocardiographers and cardio- thoracic surgeons $[38,39]$.The management plan is tailored for each case putting into consideration the anticipated 
risk of hemodynamic instability, the available medical resources, presence of feto-maternal complications, the availability and the transportation distance to a specialized cardiac center [39]. Based on our FE findings; delivery in a tertiary care center with availability of pediatric cardiologist for early neonatal echocardiographic confirmation and subsequent management was decided for all cases with cardiac abnormalities. Arrangement for future pacemaker was done for congenital heart block. Successful antiarrhythmic fetal therapy for SVT cases was done. Prevention of termination with strict follow up was the decision taken for cases with expected spontaneous resolution such as ectopics, cardiomyopathy, rhabdomyoma and even the complex structural heart diseases as termination could not have been offered for such cases based on our cultural and religious backgrounds.

Some studies have shown that neonates with CHD diagnosed antenatally tend to be born earlier than expected when compared to those diagnosed postnatally [40]. Though, the decision for the delivery timing of a neonate with a prenatal diagnosis of CHD is affected greatly by the presence or absence of maternal or fetal complications, the advantages of term delivery should be always kept in mind [39]. In our study, most of our cases were term deliveries. This reflects the high standard of obstetric care offered to our population.

\section{Study strengths and limitations}

Former studies showed that the outcome of neonates who had been diagnosed prenatally with a serious CHD and had consequently been offered an appropriate management in their early neonatal period had shown a better outcome in comparison with those diagnosed in their postnatal period [41]. Unfortunately, based on our study design which lacked a control group, we were not able to compare between pregnant mothers who had undergone prenatal FE and those who had not as regards to the perinatal outcome; hence we reported the outcome of our cases in a descriptive manner rather than a numerical one.

This study summarizes the current practice in our institution. Unlike many of the previous studies; it did not only include structural cardiac abnormalities but it also included fetal rhythm abnormalities. Moreover it highlighted the perinatal risk factors frequently encountered in our community but unfortunately; it was limited by the number of cases who did not come for follow up, so postnatal confirmation of the underlying anomaly was not done for all the studied cases.

\section{Conclusions}

CHDs exist in fetuses with no underlying perinatal risk factors. FE can accurately diagnose most of the cardiac anomalies though few errors remain challenging regarding the prenatal diagnosis of aortic coarctation. It also offers a good chance for successful early lifesaving management of some types of fetal arrhythmia. It is important to raise the awareness of the obstetricians and the obstetric-sonographers to refer pregnant mothers for $\mathrm{FE}$ in an adequate time when indicated. It is also important to improve the training of the obstetric sonographers to adequately screen for CHD with every follow up visit; owing to the evolving nature of some cardiac lesions; and to refer for FE once suspected. Moreover, there is a growing need to increase the clinical skills of the pediatric cardiologists in the field of FE.

\section{Abbreviations}

ART: assisted reproductive technology; CHDs: congenital heart defects; FE: fetal echocardiography; GA: gestational age; IUFD: intrauterine fetal death; SVT: supraventricular tachycardia; US: ultrasound.

\section{Acknowledgements \\ We thank the pregnant mothers who participated in this study.}

\section{Authors' contributions}

Author 1 (MM) collected, analyzed the data, wrote the manuscript. This work offered a good opportunity for Author 1 to be trained in fetal echocardiography under the supervision of Author 4 (NM) who performed the fetal echocardiographic examinations, conceived the idea and designed the study model. Author 2 (NA) collected and analyzed the data. Author 3 (AR) conceived the idea and designed the study model. All authors revised and approved the final manuscript.

\section{Funding}

None

Availability of data and material

All data generated or analyzed during this study are included in this published article.

\section{Declarations}

Ethical approval and consent to participate

Ethical Approval: This research protocol was approved by the Ethics committee of the Pediatric Department, Ain Shams University. Committee Reference number: not available. Consent to participate: written informed consents were obtained from the pregnant mothers.

Consent for publication

Written informed consents were obtained from the pregnant mothers.

\section{Competing interests}

The authors state that they have no competing interests.

\footnotetext{
Author details

1Pediatric Department, Pediatric Cardiology Unit, Faculty of Medicine, Ain Shams University, Ramsis Street, Abbasia, Cairo 11566, Egypt. ${ }^{2}$ Ultrasound Special Care Unit for the Fetus, Faculty of Medicine, Ain Shams University, Ramsis Street, Abbasia, Cairo 11566, Egypt. ${ }^{3}$ Present Address: Al-Salam International Hospital, Bneid Al Gar, Kuwait City, Kuwait.
} 
Received: 12 February 2021 Accepted: 2 August 2021

Published online: 19 August 2021

\section{References}

1. Donofrio MT, Moon-Grady AJ, Hornberger LK, Copel JA, Sklansky MS, Abuhamad A et al (2014) Diagnosis and treatment of fetal cardiac disease: a scientific statement from the American Heart Association. Circulation 129(21):2183-2242. https://doi.org/10.1161/01.cir.0000437597. $44550.5 d$

2. Hamdan MA, Chedid F, Bekdache GN, Begam M, Alsafi W, Sabri Z, Mirghani HM (2015) Perinatal outcome of congenital heart disease in a population with high consanguinity. J Perinat Med 43(6):735-740. https://doi.org/10.1515/jpm-2014-0019

3. Sheridan E, Wright J, Small N, Corry PC, Oddie S, Whibley C et al (2013) Risk factors for congenital anomaly in a multiethnic birth cohort: an analysis of the born in Bradford study. Lancet 382:1350-1359. https:// doi.org/10.1016/S0140-6736(13)61132-0

4. Liu S, Joseph KS, Lisonkova S, Rouleau J, Van den Hof M, Sauve R et al (2013) Association between maternal chronic conditions and congenital heart defects: a population-based cohort study. Circulation 128:583-589. https://doi.org/10.1161/CIRCULATIONAHA.112.001054

5. Bernstein D (2000) Epidemiology of congenital heart disease. In: Behrman RE, Kliegman RM, Jenson HB (eds) Nelson textbook of pediatrics. WB Saunders, Philadelphia, pp 1362-1363

6. Meberg A, Hals J, Thaulow E (2007) Congenital heart defects-chromosomal anomalies, syndromes and extracardiac malformations. Acta Paediatr 96:1142-1145. https://doi.org/10.1111/j.1651-2227.2007. 00381.x

7. Buskens E, Stewart PA, Hess J, Grobbee DE, Wladimiroff W (1996) Efficacy of fetal echocardiography and yield by risk category. Obstet Gynecol 87:423-428. https://doi.org/10.1016/0029-7844(95)00439-4

8. Mahle WT, Clancy RR, McGaurn SP, Goin JE, Clark BJ (2001) Impact of prenatal diagnosis on survival and early neurologic morbidity in neonates with the hypoplastic left heart syndrome. Pediatrics 107:12771282. https://doi.org/10.1542/peds.107.6.1277

9. Swanson TM, Selamet Tierney ES, Tworetzky W, Pigula F, McElhinney DB (2009) Truncus arteriosus: diagnostic accuracy, outcomes, and impact of prenatal diagnosis. Pediatr Cardiol 30(3):256-261. https://doi.org/10. 1007/s00246-008-9328-7

10. Morris SA, Ethen MK, Penny DJ, Canfield MA, Minard CG, Fixler DE et al (2014) Prenatal diagnosis, birth location, surgical center, and neonata mortality in infants with hypoplastic left heart syndrome. Circulation 129:285-292. https://doi.org/10.1161/CIRCULATIONAHA.113.003711

11. Cohen MS, Schultz AH, Tian ZY, Donaghue DD, Weinberg PM, Gaynor JW et al (2006) Heterotaxy syndrome with functional single ventricle: does prenatal diagnosis improve survival? Ann Thorac Surg 82:16291636. https://doi.org/10.1016/j.athoracsur.2006.05.039

12. Srinivasan S, Strasburger J (2008) Overview of fetal arrythmias. Curr Opin Pediatr 20(5):522-531. https://doi.org/10.1097/MOP.0b013e3283 of93ec

13. Hofstaetter C, Hansmann M, Eik-Nes SH, Huhta JC, Luther SL (2006) A cardiovascular profile score in the surveillance of fetal hydrops. J Matern Fetal Neonatal Med 19(7):407-413. https://doi.org/10.1080/ 14767050600682446

14. Makrydimas G, Sotiriadis A, loannidis JP (2003) Screening performance of first-trimester nuchal translucency for major cardiac defects: a metaanalysis. Am J Obstet Gynecol 189(5):1330-1335. https://doi.org/10. 1067/s0002-9378(03)00645-8

15. Volpe P, Tuo G, De Robertis V, Campobasso G, Marasini M, Tempesta A, Gentile M, Rembouskos G (2010) Fetal interrupted aortic arch: 2D-4D echocardiography, associations and outcome. Ultrasound Obstet Gynecol 35(3):302-309. https://doi.org/10.1002/uog.7530

16. Allan LD (1995) Echocardiographic detection of congenital heart disease in the fetus: present and future. Br Heart J 74:103-106. https:// doi.org/10.1136/hrt.74.2.103

17. Rychik J, Ayres N, Cuneo B, Gotteiner N, Hornberger L, Spevak PJ et al (2004) American society of echocardiography guidelines and standards for performance of the fetal echocardiogram. J Am Soc Echocardiogr 17(7):803-810. https://doi.org/10.1016/j.echo.2004.04.011
18. Meyer-Wittkopf M, Cooper S, Sholler G (2001) Correlation between fetal cardiac diagnosis by obstetric and pediatric cardiologist sonographers and comparison with postnatal findings. Ultrasound Obstet Gynecol 17:392-397. https://doi.org/10.1046/j.1469-0705.2001.00381.x

19. Chaubal NG, Chaubal J (2009) Fetal echocardiography. Indian J Radiol Imaging 19(1):60-68

20. Allan L, Benacerraf B, Copel JA, Carvalho JS, Chaoui R, Eik-Nes SH, Tegnander E, Gembruch U, Huhta JC, Pilu G, Wladimiroff J, Yagel S (2001) Isolated major congenital heart disease. Ultrasound Obstet Gynecol 17:370-379. https://doi.org/10.1046/j.1469-0705.2001.00439.x

21. Buskens E, Grobbee DE, Frohn-Mulder IM, Stewart PA, Juttmann RE, Wladimiroff JW, Hess J (1996) Efficacy of routine fetal ultrasound screening for congenital heart disease in normal pregnancy. Circulation 94(1):67-72. https://doi.org/10.1161/01.cir.94.1.67

22. Nayak K, Chandra GSN, Shetty R, Narayan PK (2016) Evaluation of fetal echocardiography as a routine antenatal screening tool for detection of congenital heart disease. Cardiovasc Diagn Ther 6(1):44-49. https:// doi.org/10.3978/j.issn.2223-3652.2015.12.01

23. Archiron R, Glaser J, Gelernter I, Hegesh J, Yagel S (1992) Extended fetal echocardiographic examination for detecting cardiac malformations in low risk pregnancies. BMJ 304:671-674. https://doi.org/10.1136/bmj. 304.6828.671

24. Carvalho JS, Mavrides E, Shinebourne EA, Campbell S, Thilaganathan B (2002) Improving the effectiveness of routine prenatal screening for major congenital heart defects. Heart 88:387-391. https://doi.org/10. 1136/heart.88.4.387

25. Chitra N, Vijayalakshmi IB (2017) Fetal echocardiography for early detection of congenital heart diseases. J Echocardiogr 15(1):13-17. https://doi.org/10.1007/s12574-016-0308-2

26. Jaeggi E, Sholler GF, Jones O, Cooper SG (1998) Impact of fetal echocardiography on the course of major congenital heart disease: a population based study. J Am Coll Cardiol 31(Suppl.):71A

27. Li M, Wang W, Yang X, Yan Y, Wu Q (2008) Evaluation of referral Indications for fetal echocardiography in Beijing. J Ultrasound Med 27:1291-1296. https://doi.org/10.7863/jum.2008.27.9.1291

28. Vaidyanathan B, Kumar S, Sudhakar A, Kumar RK (2013) Conotruncal anomalies in the fetus: referral patterns and pregnancy outcomes in a dedicated fetal cardiology unit in South India. Ann Pediatr Cardiol 6:15-20. https://doi.org/10.4103/0974-2069.107227

29. Knowles RL, Ridout D, Crowe S, Bull C, Wray J, Tregay J, Franklin RC, Barron DJ, Cunningham D, Parslow RC, Brown KL (2017) Ethnic and socioeconomic variation in incidence of congenital heart defects. Arch Dis Child 102(6):496-502. https://doi.org/10.1136/archdischi Id-2016-311143

30. Zhang YF, Zeng XL, Zhao EF, Lu HW (2015) Diagnostic value of fetal echocardiography for congenital heart disease: a systematic review and meta-analysis. Medicine (Baltimore) 94:e1759. https://doi.org/10. 1097/MD.0000000000001759

31. Soongswang J, Thitadilok W, Suansaneevithayaakul P, Sutanthavibul A, Ruangvutilert P, Wansanit K, Punlee K, Phrudprisan S, Kangkakate C (2005) Efficacy of fetal echocardiography and an evaluation of indication. J Med Assoc Thai 88(Suppl 8):S215-S220

32. Buyens A, Gyselaers W, Coumans A, Al Nasiry S, Willekes C, Boshoff D, Frijns JP, Witters I (2012) Difficult prenatal diagnosis: fetal coarctation. Facts Views Vis Obstet Gynaecol 4(4):230-236

33. Wilson NJ, Allen BC, Clarkson PM, Knight DB, Roberts AB, Calder AL (1993) One year audit of a referral fetal echocardiography service. NZ Med J 107:258-260

34. Yagel S, Weissman A, Rotstein Z, Manor M, Hegesh J, Anteby E, Lipitz S, Archiron R (1997) Congenital heart defects: natural course and in utero development. Circulation 96:550-555. https://doi.org/10.1161/01.cir. 96.2 .550

35. Simpson JM (2000) Hypoplastic left heart syndrome. Ultrasound Obstet Gynecol 15:271-278. https://doi.org/10.1046/j.1469-0705.2000.00086.x

36. Strasburger JF, Cheulkar B, Wichman HJ (2007) Perinatal arrythmias: diagnosis and management. Clin Perinatol 34:627-652. https://doi.org/ 10.1016/j.clp.2007.10.002

37. Sklansky M, Tang A, Levy D, Grossfeld P, Kashani I, Shaughnessy R et al (2002) Maternal psychological impact of fetal echocardiography. J Am Soc Echocardiogr 15:159-166 
38. Brown KL, Sullivan ID (2014) Prenatal detection for major congenital heart disease: a key process measure for congenital heart networks. Heart 100(05):359-360. https://doi.org/10.1136/heartjnl-2013-305161

39. Donofrio MT (2018) Predicting the future: delivery room planning of congenital heart disease diagnosed by fetal echocardiography. Am J Perinatol 35(6):549-552. https://doi.org/10.1055/s-0038-1637764

40. Peyvandi S, Nguyen TA, Almeida-Jones M, Boe N, Rhee L, Anton T, Sklansky M, Tarsa M, Satou G, Moon-Grady AJ, University of California Fetal Consortium (UCfC) (2017) Timing and mode of delivery in prenatally diagnosed congenital heart disease: an analysis of practices within the University of California Fetal Consortium (UCFC). Pediatr Cardiol 38(3):588-595. https://doi.org/10.1007/s00246-016-1552-y
41. Holland BJ, Myers JA, Woods CR Jr (2015) Prenatal diagnosis of critical congenital heart disease reduces risk of death fromcardiovascular compromise prior to planned neonatal cardiac surgery: a metaanalysis. Ultrasound Obstet Gynecol 45(06):631-638. https://doi.org/10.1002/ uog. 14882

\section{Publisher's Note}

Springer Nature remains neutral with regard to jurisdictional claims in published maps and institutional affiliations.

\section{Submit your manuscript to a SpringerOpen ${ }^{\circ}$ journal and benefit from:}

- Convenient online submission

- Rigorous peer review

- Open access: articles freely available online

- High visibility within the field

- Retaining the copyright to your article

Submit your next manuscript at $\boldsymbol{\nabla}$ springeropen.com 